\title{
Development of poly(lactide-co-glycolide) nanoparticles functionalized with a mitochondria penetrating peptide
}

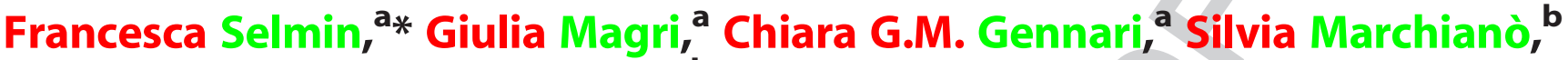 \\ Nicola Ferríc and Sara Pellegrino ${ }^{\mathbf{d} *}$ ()
}

\begin{abstract}
The development of mitochondria-targeting cell permeable vectors represents a promising therapeutic approach for several diseases, such as cancer and oxidative pathologies. Nevertheless, access to mitochondria can be difficult. A new hybrid material composed by poly(lactide-co-glycolide) (PLGA) functionalized with a 6-mer mitochondria penetrating peptide (MPP), consisting in alternating arginine and unnatural cyclohexylalanine, was developed. Circular dichroism, FT-IR and DSC studies indicated that the conjugation of the peptide with the polymer led to the obtainment of a more rigid material with respect to both PLGA and MPP as such. In particular, a conformational rearrangement to a helical structure was observed for MPP. MPP-PLGA conjugates were used for the preparation of nanoparticles that showed no cytotoxicity in MTT assay, suggesting their putative use for future studies on mitochondria targeting. Copyright @ 2016 European Peptide Society and John Wiley \& Sons, Ltd.
\end{abstract}

Keywords: conformational study; hybrid polymers; mitochondria penetrating peptide; nanoparticles; poly(lactide-co-glycolide); polymerpeptide

\section{Introduction}

In the last years, nanomaterials have gained an increasing interest in a wide range of applications, from biomedicine to catalysis and electrochemistry.[1-8] Hybrid biomaterials, that is, systems created from components of at least two distinct classes of molecules, lead to new materials that possess unprecedented levels of structural organization and novel properties at molecular level.[9-12] In the pharmaceutical field, polymer-derived nano-sized drug delivery systems have been developed to enhance pharmacokinetics and metabolic stability.[13-15] In particular, the decoration of polymers with functional peptides is a powerful approach to design nanosystems able to deliver payloads directly to the cell of interest.[16,17]

The copolymers of lactic and glycolic acids (PLGA) are among the few polymers approved by the Food and Drug Administration for human clinical applications such as surgical sutures, implantable devices and drug delivery systems because of their excellent biocompatibility and biodegradability.[18] Recently, it has been reported the PLGA functionalization with different functional peptides, such as cell penetrating octa-arginine (R8) and carrier peptides.[19,20] It has been shown that polymer characteristics, as well as nanoparticle size and surface modifications, play an important role in determining the efficacy and the biodistribution of these nanocarriers. Furthermore, the nanoparticle fabrication process could also affect their efficiency and the toxicity.

In this work, we aimed to develop a new hybrid material composed by PLGA functionalized with a mitochondria-penetrating peptide, a peptide composed of alternating cationic (arginine) and apolar (cyclohexylalanine) residues (MPP).[21,22] Engineering an efficient mitochondria-targeting cell permeable vector is challenging, because of the inner membrane structure that results impermeable against a wide range of molecules.[23] Being cationic and lipophilic at the same time, MPP is able to enter the mitochondria and, covalently linked to bioactive compounds, has been used as cellular cargo.[22] To the best of our knowledge, it has not been used for the functionalization of polymeric nanoparticles. Here, we studied the conjugation of MPP to PLGA, the effect of the polymer on peptide conformation, and we set up suitable protocols for the obtainment of nanoparticles. Finally, the cytotoxicity of the new hybrid nano-material was evaluated.

\section{Materials and Methods}

\section{Materials}

Fmoc Rinkamide resin, Fmoc-protected (L)-amino acids, HBTU $(N, N$, $N^{\prime}, N^{\prime}$-Tetramethyl-O-(1H-benzotriazol-1-yl)uronium hexafluorophosphate), HOBt (1-Hydroxybenzotriazole hydrate) and DIPEA ( $\mathrm{N}, \mathrm{N}-$

\footnotetext{
* Correspondence to: Dr. Sara Pellegrino and Dr. Francesca Selmin. E-mail: sara. pellegrino@unimi.it; francesca.selmin@unimi.it

a Department of Pharmaceutical Sciences, Università degli Studi di Milano, via G. Colombo, 71, 20133, Milano, Italy

b Department of Pharmacological and Biomolecular Sciences, via Balzaretti, 9 20133, Milano, Italy

c Department of Pharmaceutical and Pharmacological Sciences, University of Padua, Padua, Italy

d Department of Pharmaceutical Sciences, Università degli Studi di Milano, via Venezian, 21, 20133, Milano, Italy
} 
Diisopropylethylamine) were purchased from Iris Biotech Gmbh (Marktredwitz, Germany). Solvents, piperidine and other reagents were purchased from Sigma-Aldrich (Darmstadt, Germany). Uncapped poly(D,L-lactide-co-glicolide) (PLGA) [batch characteristics: lactide/glycolide mole ratio: 50:50; $M_{w}=11 \pm 0.1 \mathrm{kDa}$; $\mathrm{DI}=1.5 \pm 0.1 ; \mathrm{T}_{\mathrm{g}}=37.9 \pm 0.5^{\circ} \mathrm{C}$ ] was purchased from Lakeshore Biomaterials (Birmingham, USA).

MPP was synthesized using a CEM Liberty peptide synthesizer (Matthews, NC, USA) and purified using RP-HPLC with a Jasco (Easton, MD, USA) BS-997-01 instrument and a DENALI C-18 column from GRACE VYDAC $(10 \mu \mathrm{m}, 250 \times 22 \mathrm{~mm}$; Columbia, Maryland, USA). ESI mass spectra were recorded on a LCQ Advantage spectrometer from Thermo Finnigan (Waltham, MA USA). ${ }^{1} \mathrm{H}-\mathrm{NMR}$ spectra were acquired on a Bruker (Millerica, MA, USA) Advance 300 Spectrometer. Circular dichroism (CD) spectra were recorded on a Jasco (Easton, MD, USA) J-810 spectropolarimeter. Infrared spectra were recorded on a FT-IR spectrometer Perkin-Elmer (Waltham, MA USA) 16 PC. The gel permeation chromatography (GPC) system consisted of two $\mu$ Styragel ${ }^{\mathrm{TM}}$ columns connected in series $\left(7.8 \times 300 \mathrm{~mm}\right.$ each, one with $10^{4} \AA$ pores and one with $10^{3} \AA$ p pores), delivery device (HP 1100 Series, ChemStations Hewlett Packard, Agilent Technologies, Santa Clara, USA), refractive index detector, UV/visible detector set at $\lambda=210 \mathrm{~nm}$ and software to compute molecular weight distribution (Agilent, USA). The thermal properties of PLGA and its conjugates were characterized by a DSC 1 (Mettler Toledo, Greifensee, $\mathrm{CH}$ ) equipped with a refrigerated cooling system. Nanoparticles were characterized by photon correlation spectroscopy (PCS) and by Phase Analysis Light Scattering (M3-PALS), using a dynamic light scatter Zetasizer Nano ZS (Malvern Instrument, Worcestershire, UK), equipped with a backscattered light detector.

\section{Synthesis of the Mitochondria-Penetrating Peptide (MPP)}

MPP (H-Cha-Arg-Cha-Arg-Cha-Arg- $\mathrm{NH}_{2}$ ) was prepared by microwave-assisted solid phase synthesis[24] on Rinkamide resin $(0.57 \mathrm{meq} / \mathrm{g})$ as solid support. A fivefold molar excess of Fmocprotected amino acids ( $0.2 \mathrm{M}$ in $\mathrm{N}$-methyl pyrrolidinone) and HOBt/HBTU/DIEA (5: $5: 10$ eq) as activators were used. Coupling reactions were performed for $5 \mathrm{~min}$ at $40 \mathrm{~W}$ with a maximum temperature of $75^{\circ} \mathrm{C}$. Deprotection was performed twice using $20 \%$ piperidine in dimethylformamide (5 and $10 \mathrm{~min}$ each). Cleavage from the resin was performed using $10 \mathrm{ml}$ of Reagent $\mathrm{K}$ (trifluoroacetic acid/phenol/water/thioanisole/1,2-ethanedithiol; $82.5: 5: 5: 5: 2.5)$ for $180 \mathrm{~min}$. Following cleavage, the labelled peptide was precipitated and washed using ice-cold anhydrous ethyl ether. The peptide was purified by RP-HPLC using a gradient elution of $5-70 \%$ solvent B (solvent A: water/acetonitrile/ trifluoroacetic acid $95: 5: 0.1$; solvent $\mathrm{B}$ : water/acetonitrile/ trifluoroacetic acid $5: 95: 0.1)$ over $20 \mathrm{~min}$ at a flow rate of $20 \mathrm{ml} / \mathrm{min}$. The purified peptide was freeze-dried and stored at $0{ }^{\circ} \mathrm{C}$. MPP was then analysed by ESI(+)-MS confirming the $M_{w}$ : Mw calcd. 943.09; Mw found $473.81\left[\left(\mathrm{M}_{\mathrm{w}}+2\right) / 2\right]+1$, $316.27\left[\left(\mathrm{M}_{\mathrm{w}}\right.\right.$ $+3) / 3]+1 .{ }^{1} \mathrm{H}-\mathrm{NMR}(300 \mathrm{MHz}, \mathrm{DMSO}, \mathrm{T}=323 \mathrm{~K}) \delta \mathrm{ppm}: 0.86-0.88$ $(\mathrm{m}, 6 \mathrm{H}), 1.14-1.33(\mathrm{~m}, 13 \mathrm{H}), 1.50-1.91(\mathrm{~m}, 32 \mathrm{H}), 3.12-3.23(\mathrm{~m}, 8 \mathrm{H}$ overlapped), 3.81-3.84 $(\mathrm{m}, 1 \mathrm{H}), 4.18-4.39(\mathrm{~m}, 5 \mathrm{H}), 7.12-7.25(\mathrm{~m}$, Q2 F1 13H), 7.79-7.81 (m, 3H), 8.05-8.18 (m, 3H) (Figure 1 ).

\section{Preparation of MPP-PLGA Conjugates}

PLGA (50 mg, $5 \mu \mathrm{mol})$ was dissolved in dichloromethane $(1 \mathrm{ml})$ T1 for $1 \mathrm{~h}$. HOBt and EDC HCl (Table 1) were then added, and the suspension was stirred for $0.5 \mathrm{~h}$ at rt. MPP (Table 1) previously dissolved in DMF $(0.5 \mathrm{ml})$ and DIPEA (Table 1) were added, and the mixture was left under stirring for $12 \mathrm{~h}$ at rt. Water $(2 \mathrm{ml})$ was added to reaction mixture. The aqueous layer was extracted with dichloromethane $(3 \times 2 \mathrm{ml})$. The collected organic layers were dried on $\mathrm{Na}_{2} \mathrm{SO}_{4}$, and the solvent was removed under vacuum affording a white solid (50 mg). MPP-PLGA conjugation was confirmed by FT-IR (KBr pellet) and ${ }^{1} \mathrm{H}-\mathrm{NMR}$ (DMSO-d6 at $50^{\circ} \mathrm{C}$ and $300 \mathrm{MHZ}$ ). The percentage of peptide conjugation (PC) on PLGA was calculated by ${ }^{1} \mathrm{H}$ NMR comparing the integration area of the peptide peak at about $0.9 \mathrm{ppm}$ and PLGA multiplet at $5.3 \mathrm{ppm}$.

\section{Characterization of MPP-PLGA conjugates}

\section{Gel Permeation Chromatography (GPC)}

The molecular weight of PLGA before and after conjugation reactions was measured by GPC. The chromatographic conditions were set as follow: tetrahydrofuran (THF) filtered with $0.45 \mu \mathrm{m}$ pores PTFE filter (Pall Gelman Sciences TF 450, Port Washington, USA) as mobile phase at a flow rate of $1 \mathrm{ml} / \mathrm{min}$, injection volume of $20 \mu \mathrm{l}$ and temperature analysis of $25.0 \pm 0.1^{\circ} \mathrm{C}$. Polymer samples were dissolved in THF at a concentration of $2 \mathrm{mg} / \mathrm{ml}$. The molecular weight weight-average $\left(M_{w}\right)$ and the molecular weight number-average $\left(M_{n}\right)$ of each sample were calculated using monodisperse polystyrene standards with $M_{w}$ ranging from 947 to $42300 \mathrm{Da}$.

\section{Differential Scanning Calorimetry (DSC)}

Exactly weighted polymers samples were placed into $40 \mu$ l aluminium pans and subjected to two cooling and heating cycles from $0^{\circ} \mathrm{C}$ to $80^{\circ} \mathrm{C}$ at heating and cooling rates of $20^{\circ} \mathrm{C} / \mathrm{min}$. DSC cell was purged with a dry nitrogen flow of $80 \mathrm{ml} / \mathrm{min}$. The system was calibrated using an indium standard. Data were treated with Star ${ }^{\text {e }}$ System software (Mettler Toledo, Greifensee, $\mathrm{CH}$ ). The glass transition temperatures were measured on the second heat scan.

\section{Circular Dichroism (CD)}

Stock solution was prepared in acetonitrile $(500 \mu \mathrm{mol}$ for PLGA and MPP-PLGA conjugates, $28 \mu \mathrm{mol}$ for MPP). Spectra were obtained from 195 to $250 \mathrm{~nm}$ with a $0.1 \mathrm{~nm}$ step and $1 \mathrm{~s}$ collection time per step, taking three averages. The spectrum of the solvent was subtracted to eliminate interference from cell, solvent and optical equipment. The $C D$ spectra were plotted as mean residue ellipticity $\theta$ (degree $\times \mathrm{cm}^{2} \times \mathrm{dmol}^{-1}$ ) versus wave length $\lambda(\mathrm{nm})$. Noise reduction was obtained using a Fourier-transform filter program from Jasco (Easton, MD, USA).

\section{Preparation of Nanoparticles}

Two different strategies were pursued to prepare MPP-PLGA nanoparticles (NPs), namely solvent displacement and emulsification-solvent evaporation. The former consisted on the polymer dissolution in $1 \mathrm{ml}$ of acetonitrile at the concentration of $10 \mathrm{mg} / \mathrm{ml}$ and the addition dropwise at a constant rate to $10 \mathrm{ml}$ of MilliQ ${ }^{\circledR}$ water filtered with a nylon syringe filter of $0.2 \mu \mathrm{m}$ nominal porosity. The system was maintained at $4 \pm 1{ }^{\circ} \mathrm{C}$ and stirred at $500 \mathrm{rpm}$ for $15 \mathrm{~min}$ and, then, heated until $20 \pm 1{ }^{\circ} \mathrm{C}$ for $3 \mathrm{~h}$.

The latter method involved the MPP-PLGA dissolution in $1 \mathrm{ml}$ of dichloromethane at the concentration of $4 \mathrm{mg} / \mathrm{ml}$. The 


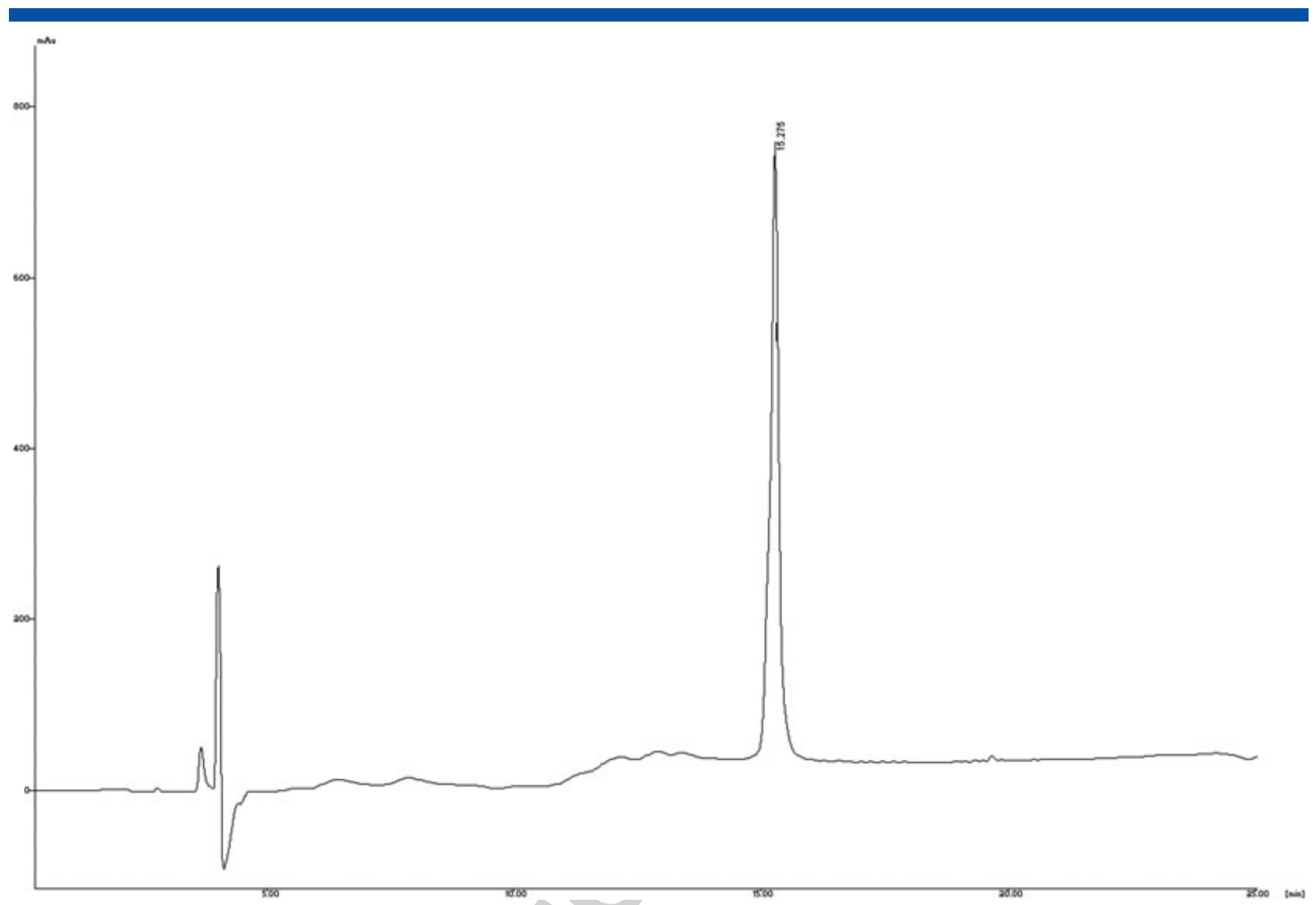

Q3 Figure 1. Analytical RP-HPLC spectrum of purified MPP (gradient elution of 5-70\% solvent B in 30 min).

Table 1. Relative amounts of PLGA, peptide, coupling reagents and base used in conjugation reaction. Percentage of peptide conjugation on PLGA (PC)

\begin{tabular}{|ccccccc} 
& PLGA & MPP & HOBt & EDC & DIPEA \\
\hline MPP-PLGA 1 & $5 \mu \mathrm{mol}$ & $5 \mathrm{mg}(5 \mu \mathrm{mol})$ & $4 \mathrm{mg}(25 \mu \mathrm{mol})$ & $5 \mathrm{mg}(25 \mu \mathrm{mol})$ & $9 \mu \mathrm{l}(50 \mu \mathrm{mol})$ \\
MPP-PLGA 2 & $5 \mu \mathrm{mol}$ & $15 \mathrm{mg}(15 \mu \mathrm{mol})$ & $3 \mathrm{mg}(15 \mu \mathrm{mol})$ & $3 \mathrm{mg}(15 \mu \mathrm{mol})$ & $6 \mu \mathrm{l}(30 \mu \mathrm{mol})$ & 30 \\
MPP-PLGA 3 & $5 \mu \mathrm{mol}$ & $15 \mathrm{mg}(15 \mu \mathrm{mol})$ & $4 \mathrm{mg}(25 \mu \mathrm{mol})$ & $5 \mathrm{mg}(25 \mu \mathrm{mol})$ & $9 \mu \mathrm{l}(50 \mu \mathrm{mol})$ & 95 \\
\hline
\end{tabular}

solution was emulsified with $2 \mathrm{ml}$ of $5 \%$ PVA $10-98$ aqueous solution using an ultrasound probe set at an amplitude of $40 \%$ for $1 \mathrm{~min}$ in ice bath. The emulsion was finally poured into $6 \mathrm{ml}$ of $0.1 \%$ PVA aqueous solution stirred at $500 \mathrm{rpm}$. The evaporation of the organic solvent was carried out over $3 \mathrm{~h}$ at about $25^{\circ} \mathrm{C}$.

\section{Characterization of NPs}

The mean hydrodynamic diameter $\left(D_{H}\right)$ and the size distribution of the nanoparticles were evaluated by PSC operating at $173^{\circ}$. All the analyses were carried out in disposable polystyrene cuvettes at a constant temperature of $25^{\circ} \mathrm{C}$, using the polystyrene latex $(\mathrm{RI}=1590)$ as reference material. The results were calculated using the Dispersion Technology Software (DTS, Malvern Instruments Ltd., Worcestershire, UK), and they are reported as intensity distribution.
The zeta potential of the nanoparticles was assessed by M3-PALS technique. The analyses were carried out into a capillary cuvette at $25^{\circ} \mathrm{C}$, with polystyrene latex as reference material.

\section{MTT Cytotoxicity Assay}

HCT -116 cells were seeded at a density of $4 \times 10^{4} /$ well in a 48 well tray and incubated with DMEM supplemented with $10 \%$ FCS; $24 \mathrm{~h}$ later, the medium was replaced with one containing MPP-PLGA 3 nanoparticles at increasing concentrations, and the cultures were incubated for $48 \mathrm{~h}$. At the end of the incubation, the cell viability was determined by MTT assay. To this purpose, MTT (Sigma-Aldrich, Darmstadt, Germany) solution was prepared at $1.5 \mathrm{mg} / \mathrm{ml}$ in RPMI without phenol red and was filtered through a $0.2 \mu \mathrm{m}$ filter. Then, the culture medium was removed from the plate, and $300 \mu \mathrm{l}$ of MTT solution was added into each well. Cells were incubated for $2 \mathrm{~h}$ at $37{ }^{\circ} \mathrm{C}$ with $5 \% \mathrm{CO}_{2}, 95 \%$ air and complete humidity. After $2 \mathrm{~h}, 200 \mu \mathrm{l}$ of 2-propanol/0.04 N HCl was added into each well, and 
the solution was resuspended. The optical density (OD) of the wells was determined using a plate reader at a wavelength of $550 \mathrm{~nm}$.

\section{Results and Discussion}

Mitochondria-penetrating peptides are synthetic cell permeable peptides that are able to enter mitochondria and are characterized by delocalized positive charge and lipophilicity. Normally, they consist in an alternating sequence of positive charged (Arg or Lys) and hydrophobic amino acids (Phe or the unnatural cyclohexylalanine, Cha). The cationic character is needed for driving the uptake of the delivery vectors through the cellular and mitochondrial membranes, both of which have a negative membrane potential. On the other hand, the passage of cations across the hydrophobic inner mitochondrial membrane is facilitated by the presence of lipophilic groups, such as benzene or cyclohexyl ring.[21,22]

In this work, we selected the 6-mer sequence H-Cha-Arg-ChaArg-Cha-Arg- $\mathrm{NH}_{2}$ (MPP) for the functionalization of a well-known biodegradable polymer as poly(lactide-co-glycolide) (PLGA). In particular, we decided to first conjugate MPP to PLGA and to characterize the main physico-chemical properties of the novel material and then to study the feasibility of the preparation of nanoparticles (Scheme 1).

MPP was prepared by MW-assisted solid phase peptide synthesis following standard procedure. MPP conjugation with PLGA was carried out in dichloromethane, using $\mathrm{HOBt}$ and $\mathrm{EDC} \mathrm{HCl}$ as coupling reagents and DIPEA as base. Different molar ratios (Table 1) were evaluated. In particular, the coupling was scarcely efficient using an equimolar ratio between PLGA and MPP and a five-fold excess of coupling reagents (MPP-PLGA 1). We then increased the amount of MPP ( $3 \mathrm{eq})$, and in the same time we reduced the amount of coupling reagents, yielding to MPP-PLGA 2 characterized by a $50 \%$ of PC. The best coupling conditions were obtained using a MPP/PLGA molar ratio of 3:1, a five-fold excess of coupling reagents and 10 equivalents of the base (MPP-PLGA 3, 95\% of PC). The of MPP-PLGA conjugates was assessed by using ${ }^{1} \mathrm{H}$ NMR spectroscopy and by setting as diagnostic for conjugation the peptide peak at $0.9 \mathrm{ppm}$ (Figure 2). In particular, we compared its area value F2 peak with that of the peak at $5.3 \mathrm{ppm}$ assignable to the polymer, as already reported in the literature for other peptide-PLGA functionalization.[20]

The conjugates were also analysed by GPC to evaluate the average molecular weight of the new hybrid polymers because PLGA is a very sensitive material and several factors can modify its

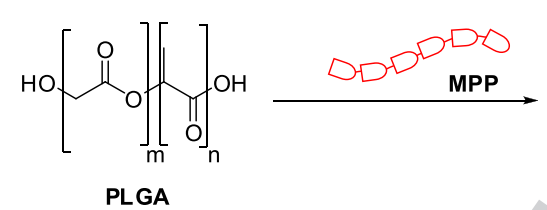

(monomer ratio $50: 50$ )

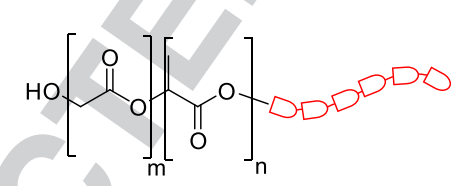

MPP-PLGA

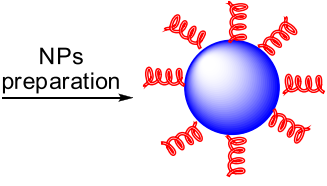

Scheme 1. Functionalization of poly(lactide-co-glycolide) (PLGA) with MPP peptide and subsequently nanoparticles preparation.

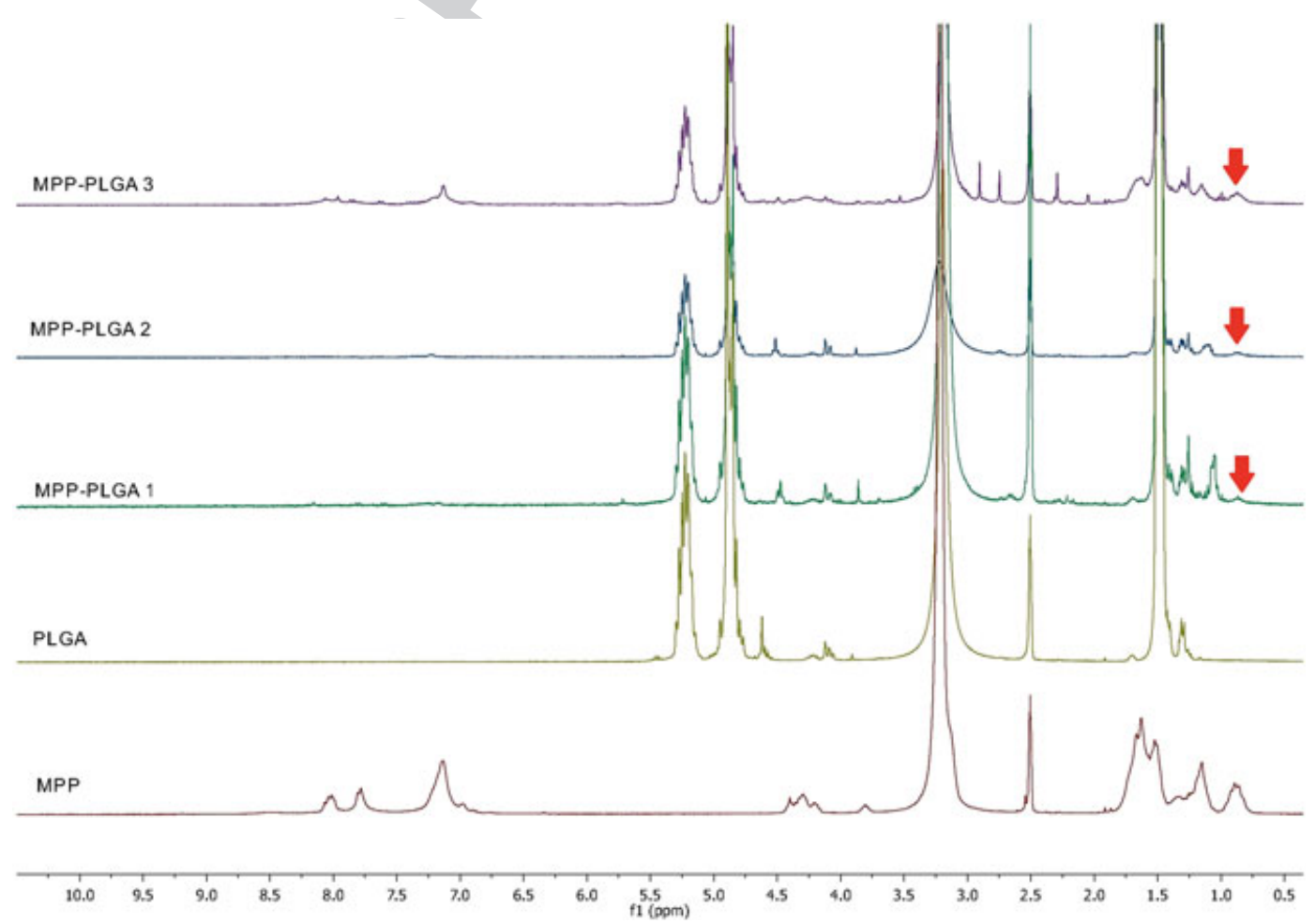

Figure 2. ${ }^{1} \mathrm{H}-\mathrm{NMR}$ spectrum of MPP, PLGA and MPP-PLGA conjugates. 
main physico-chemical features.[25] Moving from PLGA to its conjugates, the $M_{w}$ increased from about $11.0 \mathrm{kDa}$ to $13.6 \mathrm{kDa}$, confirming the ${ }^{1} \mathrm{H}-\mathrm{NMR}$ data and thus the conjugation of MPP to the polymer. Likewise, $M_{n}$ and dispersity index of the raw PLGA and MPP-PLGA conjugates overlapped at about $7.8 \mathrm{kDa}$ and 1.5 , respectively, suggesting that the conjugation conditions did not have a detrimental effect on polymer main features.

For MPP-PLGA 2 and MPP-PLGA 3, the conjugation was also F3 investigated by FT-IR analysis (Figure 3).

In both cases, the polymers were characterized by a band at $1760 \mathrm{~cm}^{-1}$ (PLGA ester stretching), a band at around $1656 \mathrm{~cm}^{-1}$ and a shoulder at $1673 \mathrm{~cm}^{-1}$ (both because of MPP amide I stretching). By comparing the FT-IR spectra of MPP alone (red curve) with MPP-PLGA conjugates (black and blue curves), a shift of amide I band frequency at $1635 \mathrm{~cm}^{-1}$ was observed, together with a decrease in intensity of the band at $1673 \mathrm{~cm}^{-1}$. Of relevance, a new band at $1656 \mathrm{~cm}^{-1}$ is observed. These data suggested that a stabilization of peptide helix structure was effective upon

F4 conjugation.[26] CD analysis was thus performed. Figure 4 reports the spectra of MPP and of MPP-PLGA 3 conjugate in acetonitrile. In solution, MPP alone did not assume a preferred conformation as underlined by a negative ellipticity value at $190 \mathrm{~nm}$ and the low intensity of the $n-\pi$ bands. For MPP-PLGA conjugate, a positive value at $190 \mathrm{~nm}$ together with negative Cotton effects at $205 \mathrm{~nm}$ and $220 \mathrm{~nm}$ of similar intensity were observed. This finding confirmed an increase of peptide helical content when MPP is bound to PLGA, and thus, an increase in the overall rigidity of the hybrid polymeric system.

Moreover, a reduction of the specific heat $\left(C_{P}\right)$ associated to the

T2 glass transition was also noticed in MPP-PLGA 3 (Table 2). Generally speaking, the decrease of $C_{P}$ is related to the increase of hydrogen bonds or the weaker Van der Waals forces, limiting the molecular mobility of the polymer chains.[27] Hence, the stiffening of the polymer structure can be because of the induction of the preferred conformation of MPP which forced PLGA to a rearrangement.

Based on the results obtained, MPP-PLGA 2 and 3 were considered as suitable candidates to prepare nanoparticles. Several methods are reported in literature for the preparation of nano-sized

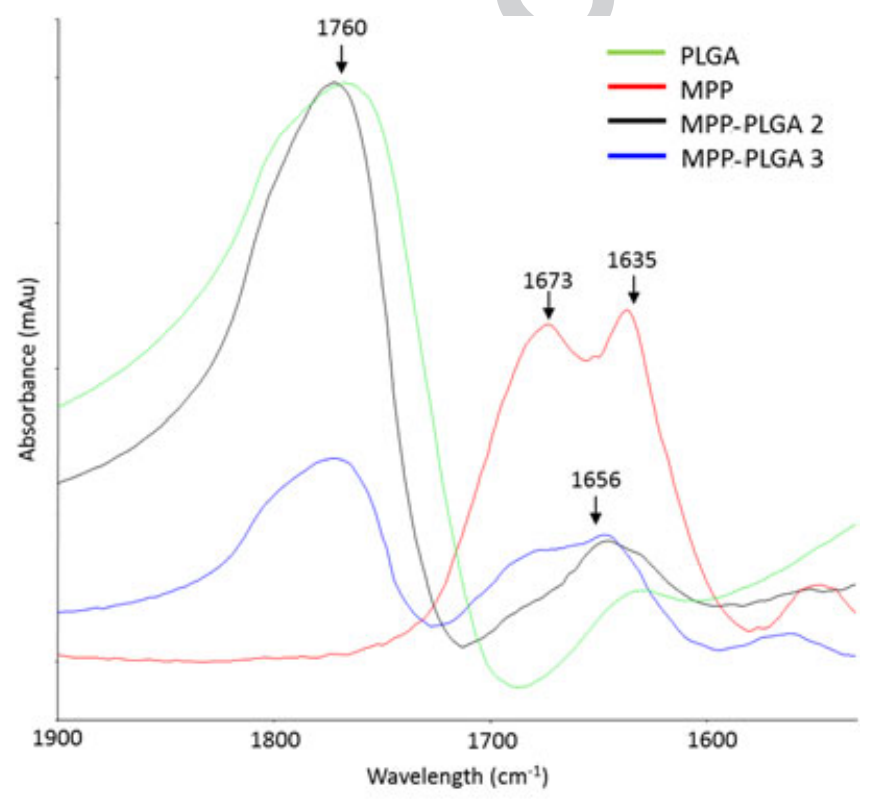

Figure 3. FT-IR spectra on $\mathrm{KBr}$ pellets.

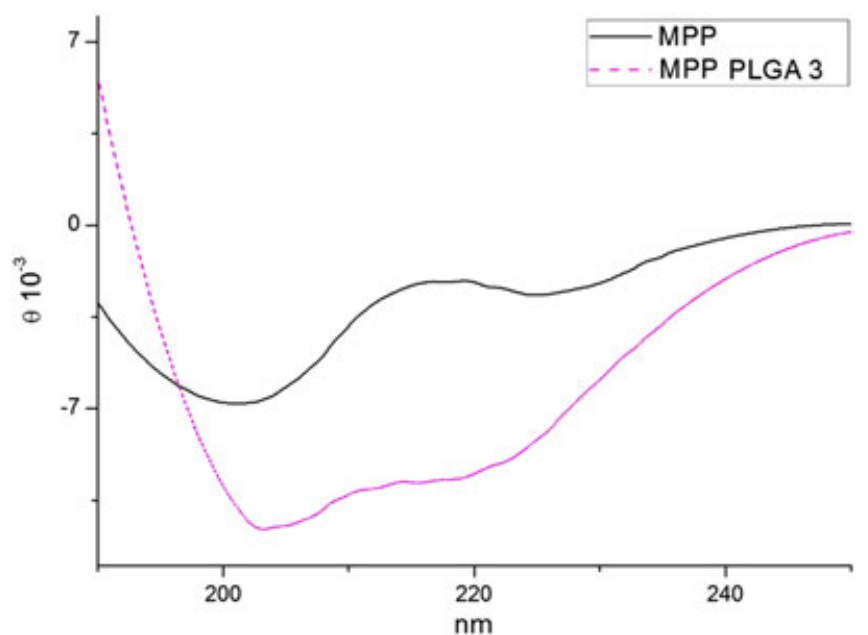

Figure 4. CD spectra of MPP alone and MPP-PLGA $3(100 \mu \mathrm{mol}$ in ACN at rt).

Table 2. Main differences in terms of glass transition temperature $\left(T_{q}\right)$ and specific heat $\left(C_{P}\right)$ resulted by the thermal analysis of the raw PLGA and PLGA conjugates

\begin{tabular}{|lcc|} 
Polymer ID & $\mathrm{T}_{\mathrm{g}}\left({ }^{\circ} \mathrm{C}\right)$ & $\mathrm{C}_{\mathrm{p}}\left(\mathrm{mW} / \mathrm{g}^{\circ} \mathrm{C}\right)$ \\
\hline PLGA & $37.9 \pm 0.5$ & $29.1 \pm 0.8$ \\
MPP-PLGA 2 & $38.9 \pm 1.0$ & $28.2 \pm 1.9$ \\
MPP-PLGA 3 & $45.8 \pm 0.2$ & $22.1 \pm 2.1$ \\
\hline
\end{tabular}

systems.[28] As a rule, an optimal method should be as simple as possible, limiting the use of excipients such as stabilizing agents that could cause toxic effects depending on their nature and amount. The solvent displacement method (also known as 'nanoprecipitation') is the most common technique reported for PLGA-based systems.[29] In a preliminary step of this work, different water-miscible organic solvents were considered for the preparation of the MPP-PLGA solution, such as acetone, acetone/absolute ethanol mixture in two volume ratios (i.e. 85/15 and 70/30) and acetonitrile. The concentration of the polymer solution was fixed at $10 \mathrm{mg} / \mathrm{ml}$. The raw PLGA was freely soluble in all solvents reported above. The acetone only or the mixture with absolute ethanol in the ratio of $85 / 15$ allowed solubilizing MPP-PLGA 2 at a maximum concentration of $5 \mathrm{mg} / \mathrm{ml}$, causing the formation of NPs with a size of about $100 \mathrm{~nm}$ (Table 3). The conjugate did not T3 dissolve in acetone/absolute ethanol 70/30. MPP-PLGA 2 resulted soluble at the prefixed concentration only in acetonitrile and the corresponding NPs presented a $D_{H}$ of $171 \pm 5 \mathrm{~nm}$ (Table 3 ).

On the other hand, MPP-PLGA 3 did not dissolve in the watermiscible solvents considered. This was probably because MPP deeply modified the physico-chemical features of the polymer. Hence, MPP-PLGA 3 was dissolved in dichloromethane in order to prepare NPs by emulsification-solvent evaporation. This method permitted the formation of NPs with a $D_{H}$ of $454 \pm 12 \mathrm{~nm}$ and a polydispersity index of $0.451 \pm 0.082$. More importantly, the conjugation with MPP resulted in a significant increase in the zeta potential of NPs from about $-35 \mathrm{mV}$ to about $1.3 \pm 0.2 \mathrm{mV}$. No signs of aggregation were noticed after the preparation of MPP-PLGA 3 NPs, probably because of the presence of residual PVA on the surface of the NPs, which permitted a particle-particle repulsion.[30] The negative zeta potential of PLGA is because of the presence of negatively charged carboxylic acid end groups. Only in NPs made 
Table 3. Hydrodynamic diameter $\left(D_{H}\right)$, polydispersity index (PDI) and zeta potential $(\xi)$ of NPs obtained by using MPP-PLGA 2 solutions in different water-miscible solvents

\begin{tabular}{|lcccc} 
Solvent & Concentration $(\mathrm{mg} / \mathrm{ml})$ & $\mathrm{D}_{\mathrm{H}}(\mathrm{nm})$ & PDI & $\xi(\mathrm{mV})$ \\
\hline Acetone & 5 & $98 \pm 2$ & $0.101 \pm 0.014$ & $-46.2 \pm 2.5$ \\
Acetone/ethanol 85/15 & 5 & $96 \pm 1$ & $0.106 \pm 0.004$ & $-45.0 \pm 1.5$ \\
Acetone/ethanol 70/30 & - & - & - & - \\
Acetonitrile & 10 & $171 \pm 5$ & $0.100 \pm 0.041$ & $-45.4 \pm 0.6$ \\
\hline
\end{tabular}

of MPP-PLGA 3, the conjugation with MPP increased the superficial charge to values near neutral. This is a further confirmation that a highest amount of positively charged MPP was linked to PLGA and was thus able to neutralize the charged carboxylic acid end groups of PLGA.

The most promising NPs obtained by MPP-PLGA 3 hybrid polymer were thus submitted to preliminary cytotoxicity studies. Cell viability was investigated in colon carcinoma cell line HCT116. As

F5 shown in Figure 5, MPP-PLGA 3 did not significantly alter the cell viability after $48 \mathrm{~h}$ incubation at concentrations up to $5 \mu \mathrm{g} / \mathrm{ml}$.

In conclusion, PLGA was successfully functionalized with 6-mer MPP peptide containing Arg and the unnatural amino acid Cha. By tuning MPP/PLGA molecular ratio and the coupling reagents' equivalent, it has been possible to obtain a hybrid polymer characterized by a higher conformational rigidity with respect to PLGA and MPP alone. Indeed, when linked to PLGA, MPP peptide underwent a conformational switch toward helical conformation that induced the stiffening of the overall polymeric structure. The new hybrid polymer was used to realize MPP functionalized PLGA NPs using both the solvent displacement and the emulsificationsolvent evaporation methods. The obtained NPs showed no toxicity in MTT cell viability test, suggesting their potential use in pharmacological application. Future investigations will be aimed to study NP mitochondria internalization and loading ability of this new hybrid material.

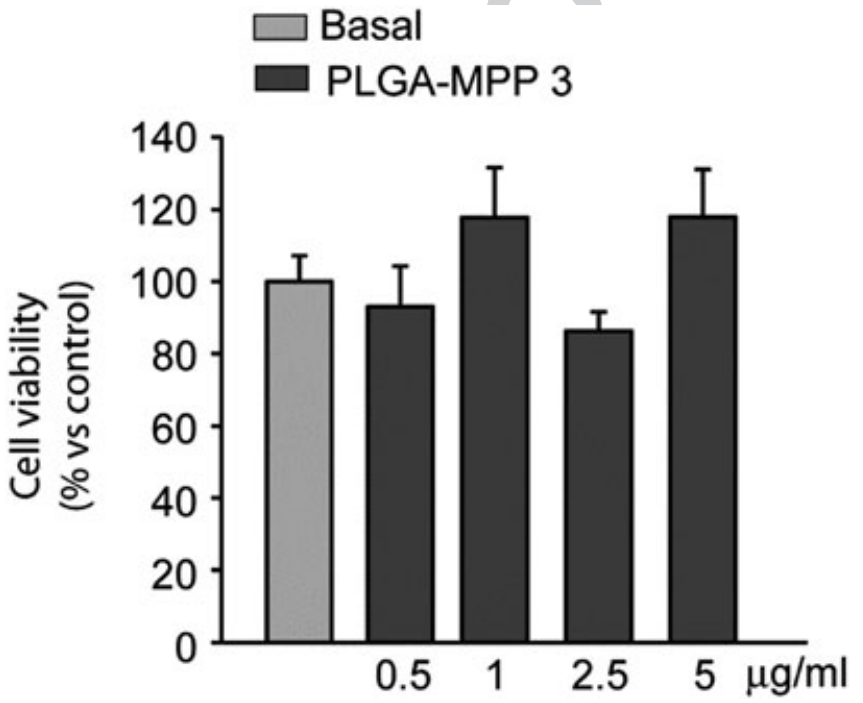

Figure 5. Cell viability after incubation with different concentrations of MPP-PLGA 3. HCT-116 cells were cultured for $48 \mathrm{~h}$ in the presence or absence of reported concentrations of PLGA-MMP 3.0, and their viability was estimated by MTT assay. Each bar represents the mean \pm standard deviation of three determinations.

\section{Acknowledgements}

Funding for this work has been provided by Università degli Studi di Milano (Piano Sviluppo, Linea B).

\section{References}

1 Habibi N, Kamaly N, Memic A, Shafiee H. Self-assembled peptidebased nanostructures: smart nanomaterials toward targeted drug delivery. Nano Today 2016; 11: 41. DOI: 10.1016/j. nantod.2016.02.004.

2 Blum AP, Kammeyer JK, Rush AM, Callmann CE, Hahn ME, Gianneschi NC. Stimuli-responsive nanomaterials for biomedical applications. J. Am. Chem. Soc. 2015; 137: 2140. DOI: 10.1021/ja510147n.

3 Irvine DJ, Hanson MC, Rakhra K, Tokatlian T. Synthetic nanoparticles for vaccines and immunotherapy. Chem. Rev. 2015; 115: 11109. DOI: 10.1021/acs.chemrev.5b00109.

4 Bonetti A, Pellegrino S, Das P, Yuran S, Bucci R, Ferri N, Meneghetti F, Castellano C, Reches M, Gelmi ML. Dipeptide nanotubes containing unnatural fluorine-substituted $\beta(2,3)$-diarylamino acid and I-alanine as candidates for biomedical applications. Org. Lett. 2015; 17: 4468. DOI: 10.1021/acs.orglett.5b02132.

5 Maione S, Gil AM, Fabregat G, del Valle $\sqcup$, Triguero J, Laurent A, Jacquemin D, Estrany F, Jiménez Al, Zanuy D, Cativiela C, Alemán C. Electroactive polymer-peptide conjugates for adhesive biointerfaces. Biomater. Sci. 2015; 3: 1395. DOI: 10.1039/C5BM00160A.

6 Torabi SF, Lu Y. Functional DNA nanomaterials for sensing and imaging in living cells. Curr. Opin. Biotech. 2014; 28: 88. DOI: 10.1016/j. copbio.2013.12.011.

7 Zhang L, Qin L, Wang X, Cao H, Liu M. Supramolecular chirality in selfassembled soft materials: regulation of chiral nanostructures and chiral functions. Adv. Mater. 2014; 26: 6959. DOI: 10.1002/adma.201305422.

$8 \mathrm{Xu} \mathrm{Y,} \mathrm{Zhang} \mathrm{B.} \mathrm{Recent} \mathrm{advances} \mathrm{in} \mathrm{porous} \mathrm{Pt-based} \mathrm{nanostructures:}$ synthesis and electrochemical applications. Chem. Soc. Rev. 2014; 43: 2439. DOI: $10.1039 /$ C3CS60351B.

9 He C, Liu D, Lin W. Nanomedicine applications of hybrid nanomaterials built from metal-ligand coordination bonds: nanoscale metal-organic frameworks and nanoscale coordination polymers. Chem. Rev. 2015; 115: 11079. DOI: 10.1021/acs.chemrev.5b00125.

10 Cobo I, Li M, Sumerlin BS, Perrier S. Smart hybrid materials by conjugation of responsive polymers to biomacromolecules. Nat. Mater. 2015; 14: 43. DOI: 10.1038/nmat4106.

11 Murase SK, Haspel N, del Valle $\amalg$, Perpète EA, Michaux C, Nussinov R, Puiggalí J, Alemán C. Molecular characterization of L-phenylalanine terminated poly(L-lactide) conjugates. RSC Adv. 2014; 4: 23231. DOI: 10.1039/C4RA01534G.

12 Sanchez C, Belleville P, Popall M, Nicole L. Applications of advanced hybrid organic-inorganic nanomaterials: from laboratory to market. Chem. Soc. Rev. 2011; 40: 696. DOI: 10.1039/COCS00136H.

13 Nicolas J, Mura S, Brambilla D, Mackiewicz N, Couvreur P. Design, functionalization strategies and biomedical applications of targeted biodegradable/biocompatible polymer-based nanocarriers for drug delivery. Chem. Soc. Rev. 2013; 42: 1147. DOI: 10.1039/c2cs35265f.

14 Sapsford E, Algar WR, Berti L, Boeneman Gemmill K, Casey BJ, Oh E, Stewart $\mathrm{MH}$, Medintz IL. Functionalizing nanoparticles with biological molecules: developing chemistries that facilitate nanotechnology. Chem. Rev. 2013; 113: 1904. DOI: 10.1021/cr300143v.

15 Farokhzad OC, Langer R. Impact of nanotechnology on drug delivery. ACS Nano 2009; 3: 16. DOI: 10.1021/nn900002m.

16 Chen $B$, He X-Y, Yi X-Q, Zhuo R-X, Cheng S-X. Dual-peptidefunctionalized albumin-based nanoparticles with $\mathrm{pH}$-dependent self- 
assembly behavior for drug delivery. ACS Appl. Mater. Interfaces 2015; 7 15148. DOI: 10.1021/acsami.5b03866.

17 Malhotra M, Prakash S. Targeted drug delivery across blood-brain-barrier using cell penetrating peptides tagged nanoparticles. Curr. Nanosci. 2011; 7: 81. DOI: 10.2174/157341311794480336.

18 Anderson JM, Shive MS. Biodegradation and biocompatibility of PLA and PLGA microspheres. Adv. Drug Del. Rev. 2012; 64: 72. DOI: 10.1016/j. addr.2012.09.004.

19 O'Donnell A, Moollan A, Baneham S, Ozgul M, Pabari RM, Cox D, Kirby BP, Ramtoola Z. Intranasal and intravenous administration of octa-arginine modified poly(lactic-co-glycolic acid) nanoparticles facilitates central nervous system delivery of loperamide. J. Pharm. Pharmacol. 2014; 67: 525. DOI: 10.1111/jphp.12347.

20 Colzani B, Biagiotti M, Speranza G, Dorati R, Modena T, Conti B, Tomasi C, Genta I. Smart biodegradable nanoparticulate materials: poly-lactide-coglycolide functionalization with selected peptides. Curr. Nanosci. 2016; 12: 347.

21 Horton KL, Stewart KM, Fonseca SB, Guo Q, Kelley SO. Mitochondriapenetrating peptides. Chem. Biol. 2008; 15: 375. DOI: 10.1016/j. chembiol.2008.03.015.

22 Yousif LF, Stewart KM, Horton KL, Kelley SO. Mitochondria-penetrating peptides: sequence effects and model cargo transport. ChemBioChem 2009; 10: 2081. DOI: 10.1002/cbic.200900017.

23 Jean SR, Tulumello DV, Wisnovsky SP, Lei EK, Pereira MP, Kelley SO. Molecular vehicles for mitochondrial chemical biology and drug delivery. ACS Chem. Biol. 2014; 9: 323. DOl: 10.1021/cb400821p.
24 Pellegrino S, Annoni C, Contini A, Clerici F, Gelmi ML. Expedient chemical synthesis of 75mer DNA binding domain of MafA: an insight on its binding to insulin enhancer. Amino Acids 2012; 43: 1995. DOI: 10.1007/ s00726-012-1274-2.

25 Selmin F, Blasi P, DeLuca PP. Accelerated polymer biodegradation of risperidone poly(D, L-lactide-co-glycolide) microspheres. AAPS PharmSciTech 2012; 13: 1465. DOI: 10.1208/s12249-012-9874-4.

26 Kong J, Yu S. Fourier transform infrared spectroscopic analysis of protein secondary structures. Acta Biochim. Biophys. Sin. 2007; 39: 549. DOI: 10.1111/j.1745-7270.2007.00320.x.

27 Gibbs JH, Di Marzio EA. Nature of the glass transition and the glassy state. J. Chem. Phys. 1958; 28: 373. DOI: 10.1063/1.1744141.

28 Lai P, Daear W, Löbenberg R, Prenner EJ. Overview of the preparation of organic polymeric nanoparticles for drug delivery based on gelatine, chitosan, poly(D,L-lactide-co-glycolic acid) and polyalkylcyanoacrylate. Colloids Surf. B 2014; 118: 154. DOl: 10.1016/ j.colsurfb.2014.03.017.

29 Fessi H, Puisieux F, Devissaguet JP, Ammoury N, Benita S. Nanocapsule formation by interfacial polymer deposition following solvent displacement. Int. J. Pharm. 1989; 55, R1: . DOI: 10.1016/03785173(89)90281-0.

30 Quintanar-Guerrero D, Ganem-Quintanar A, Allémann E, Fessi H, Doelker E. Influence of the stabilizer coating layer on the purification and freeze-drying of poly(D, L-lactic acid) nanoparticles prepared by an emulsion-diffusion technique. J. Microenc. 1998; 15: 107. DOI: 10.3109/ 02652049809006840 . 


\section{Special Issue Article}

\section{Development of poly(lactide-co-glycolide) nanoparticles functionalized with a mitochondria}

penetrating peptide

Francesca Selmin, Giulia Magri, Chiara G.M. Gennari, Silvia Marchianò, Nicola Ferri and Sara Pellegrino

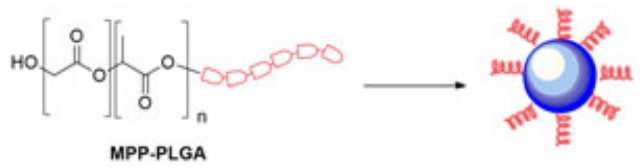

A new hybrid material composed by poly(lactide-co-glycolide) (PLGA) functionalized with a 6-mermithochondria penetrating peptide (MPP) was developed. A conformational to a helical structure was observed for MPP upon conjugation with the polymer. This new rigid material was used for the preparation of cell compatible nanoparticles. 


\section{Author Query Form}

\section{Journal: Journal of Peptide Science}

\section{Article: psc_2952}

Dear Author,

During the copyediting of your paper, the following queries arose. Please respond to these by annotating your proofs with the necessary changes/additions.

- If you intend to annotate your proof electronically, please refer to the E-annotation guidelines.

- If you intend to annotate your proof by means of hard-copy mark-up, please use the standard proofing marks. If manually writing corrections on your proof and returning it by fax, do not write too close to the edge of the paper. Please remember that illegible mark-ups may delay publication.

Whether you opt for hard-copy or electronic annotation of your proofs, we recommend that you provide additional clarification of answers to queries by entering your answers on the query sheet, in addition to the text mark-up.

\begin{tabular}{|c|l|c|}
\hline Query No. & \multicolumn{1}{|c|}{ Query } & Remark \\
\hline Q1 & $\begin{array}{l}\text { AUTHOR: Please confirm that given names (red) and surnames/family names (green) } \\
\text { have been identified correctly. }\end{array}$ & $\begin{array}{c}\text { AUTHOR: Figure1 was not cited in the text. An attempt has been made to insert the figure } \\
\text { into a relevant point in the text - please check that this is OK. If not, please provide clear } \\
\text { guidance on where it should be cited in the text. }\end{array}$ \\
\hline Q3 & AUTHOR: Revised figure 1 still contains small and poor quality of text. & \\
\hline
\end{tabular}


Required software to e-Annotate PDFs: Adobe Acrobat Professional or Adobe Reader (version 7.0 or above). (Note that this document uses screenshots from Adobe Reader $\mathrm{X}$ )

The latest version of Acrobat Reader can be downloaded for free at: http://get.adobe.com/uk/reader/

Once you have Acrobat Reader open on your computer, click on the Comment tab at the right of the toolbar:

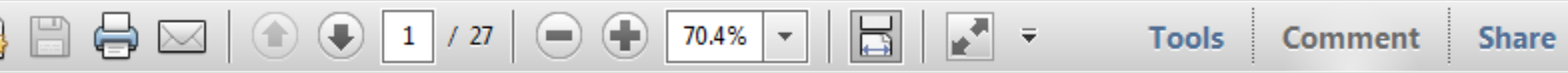

This will open up a panel down the right side of the document. The majority of tools you will use for annotating your proof will be in the Annotations section, pictured opposite. We've picked out some of these tools below:

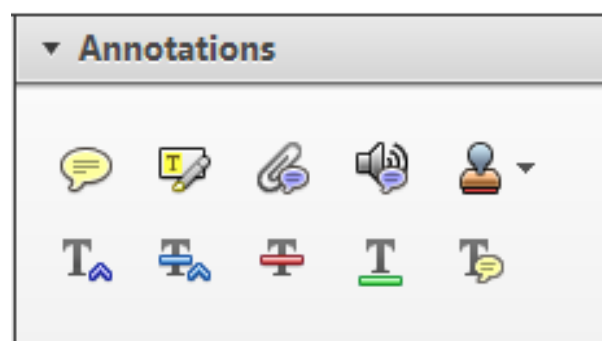

1. Replace (Ins) Tool - for replacing text.

Strikes a line through text and opens up a text box where replacement text can be entered.

How to use it

- Highlight a word or sentence.

- Click on the Replace (Ins) icon in the Annotations section.

- Type the replacement text into the blue box that appears.

Idard tramework for the analysis of $\mathrm{m}$ icy-Nevertheless, it also led to exog،

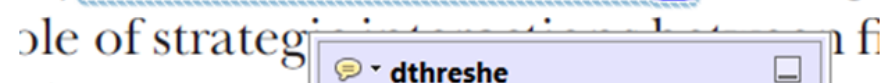
aber of comp 08/06/2011 15:58:17 is that the s1 nain compo: be level, are exc nc

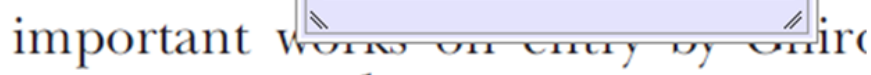
M heneferth) ${ }^{1}$ we anen the "hlarl $\mathrm{l}$

3. Add note to text Tool - for highlighting a section to be changed to bold or italic.

T Highlights text in yellow and opens up a text box where comments can be entered.

\section{How to use it}

- Highlight the relevant section of text.

- Click on the Add note to text icon in the Annotations section.

- Type instruction on what should be changed regarding the text into the yellow box that appears.

namic responses of mark ups ent with the VAR evidence

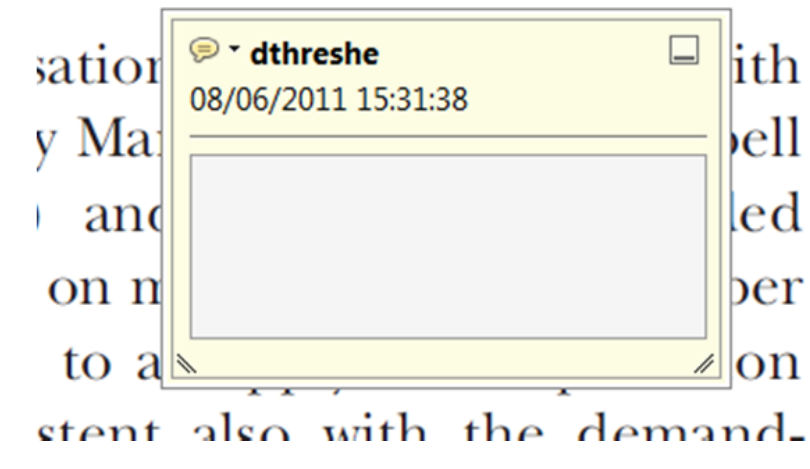

2. Strikethrough (Del) Tool - for deleting text.

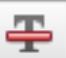

Strikes a red line through text that is to be deleted.

How to use it

- Highlight a word or sentence.

- Click on the Strikethrough (Del) icon in the Annotations section.

there is no room tor extra prohts al c ups are zero and the number of ret) values are not determined by Blanchard and Kiyotaki (1987), sfect competition in general equilil ts of aggregate demand and supply lassical framework assuming monol eph on evorenous number of firme

4. Add sticky note Tool - for making notes at specific points in the text.

Marks a point in the proof where a comment needs to be highlighted.

How to use it

- Click on the Add sticky note icon in the Annotations section.

- Click at the point in the proof where the comment should be inserted.

- Type the comment into the yellow box that appears.

iaisu airu suppiy sirucks. hivsl ui

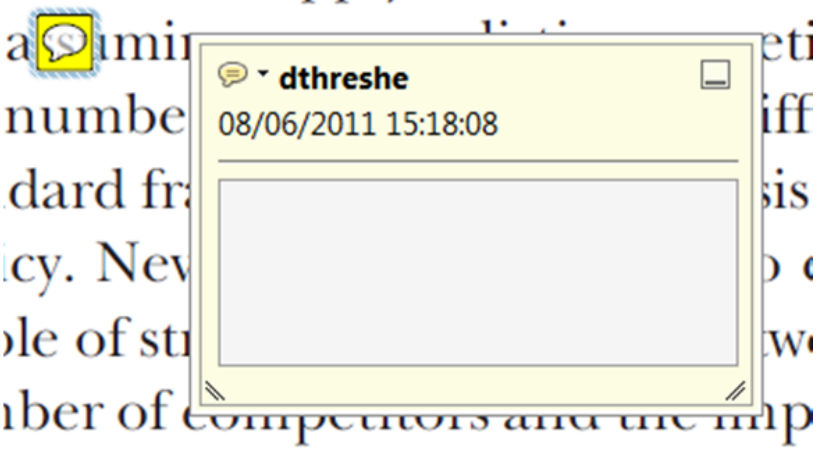

is that the structure of the secto. 
5. Attach File Tool - for inserting large amounts of text or replacement figures.

Inserts an icon linking to the attached file in the appropriate pace in the text.

How to use it

- Click on the Attach File icon in the Annotations section.

- Click on the proof to where you'd like the attached file to be linked.

- Select the file to be attached from your computer or network.

- Select the colour and type of icon that will appear in the proof. Click OK.

E N D

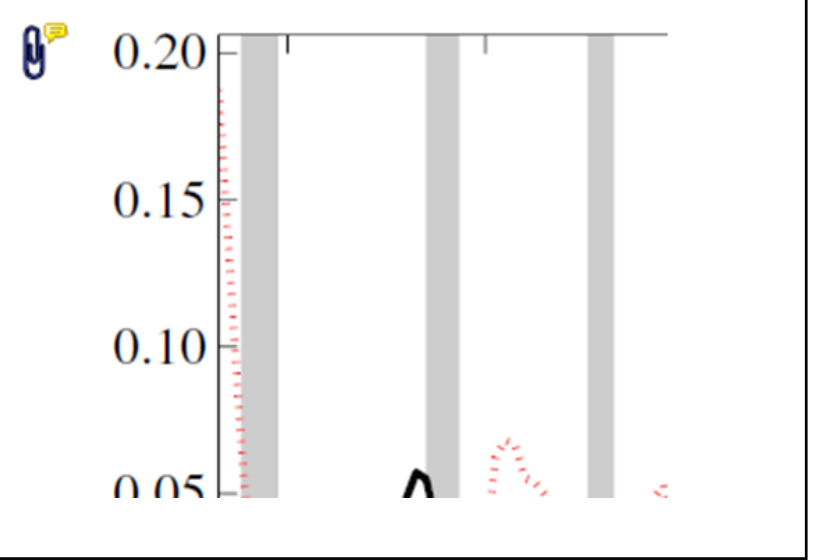

6. Add stamp Tool - for approving a proof if no corrections are required.

- Inserts a selected stamp onto an appropriate place in the proof.

\section{How to use it}

- Click on the Add stamp icon in the Annotations section.

- $\quad$ Select the stamp you want to use. (The Approved stamp is usually available directly in the menu that appears).

- Click on the proof where you'd like the stamp to appear. (Where a proof is to be approved as it is, this would normally be on the first page).

or the business cycie, starting with the on perfect competition, constant ret

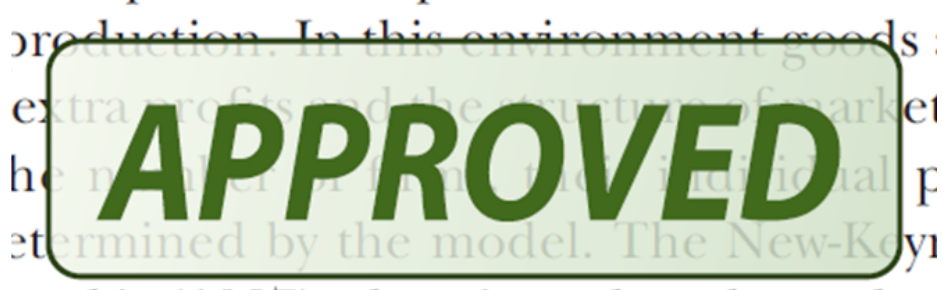
otaki (1987), has introduced produc general equilibrium models with nomin:

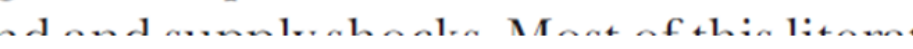

- Drawing Markups

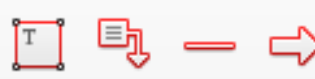

$0 \bigcirc \sqrt{6} \otimes$

\section{How to use it}

- Click on one of the shapes in the Drawing Markups section.

- Click on the proof at the relevant point and draw the selected shape with the cursor.

- To add a comment to the drawn shape, move the cursor over the shape until an arrowhead appears.

- Double click on the shape and type any text in the red box that appears.
7. Drawing Markups Tools - for drawing shapes, lines and freeform annotations on proofs and commenting on these marks.

Allows shapes, lines and freeform annotations to be drawn on proofs and for comment to be made on these marks.

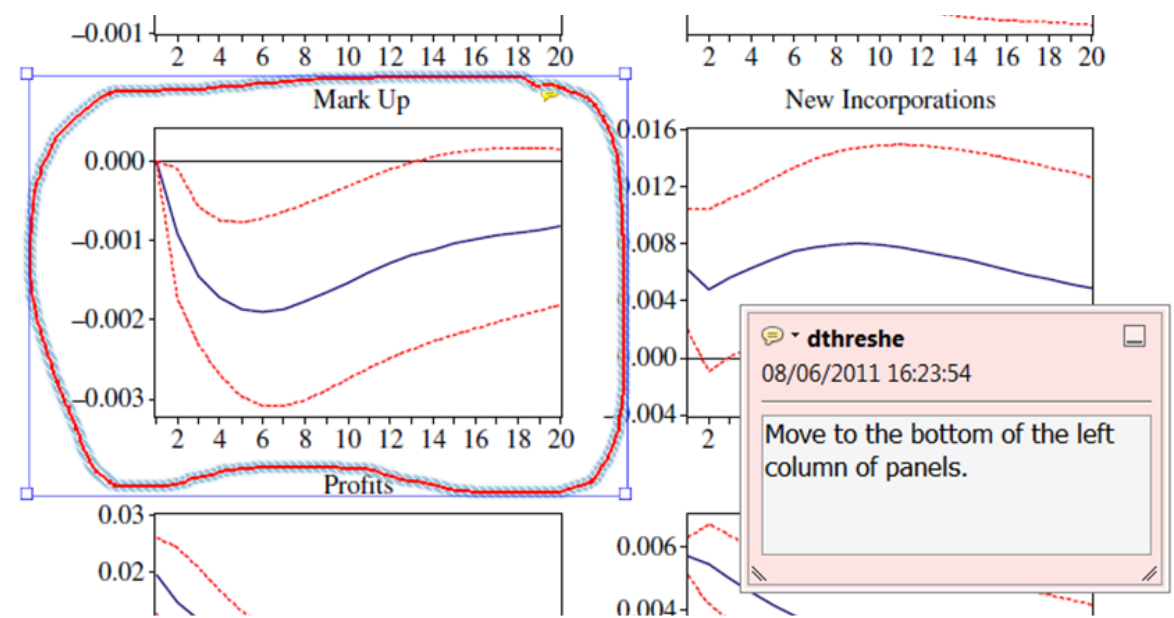

For further information on how to annotate proofs, click on the Help menu to reveal a list of further options:

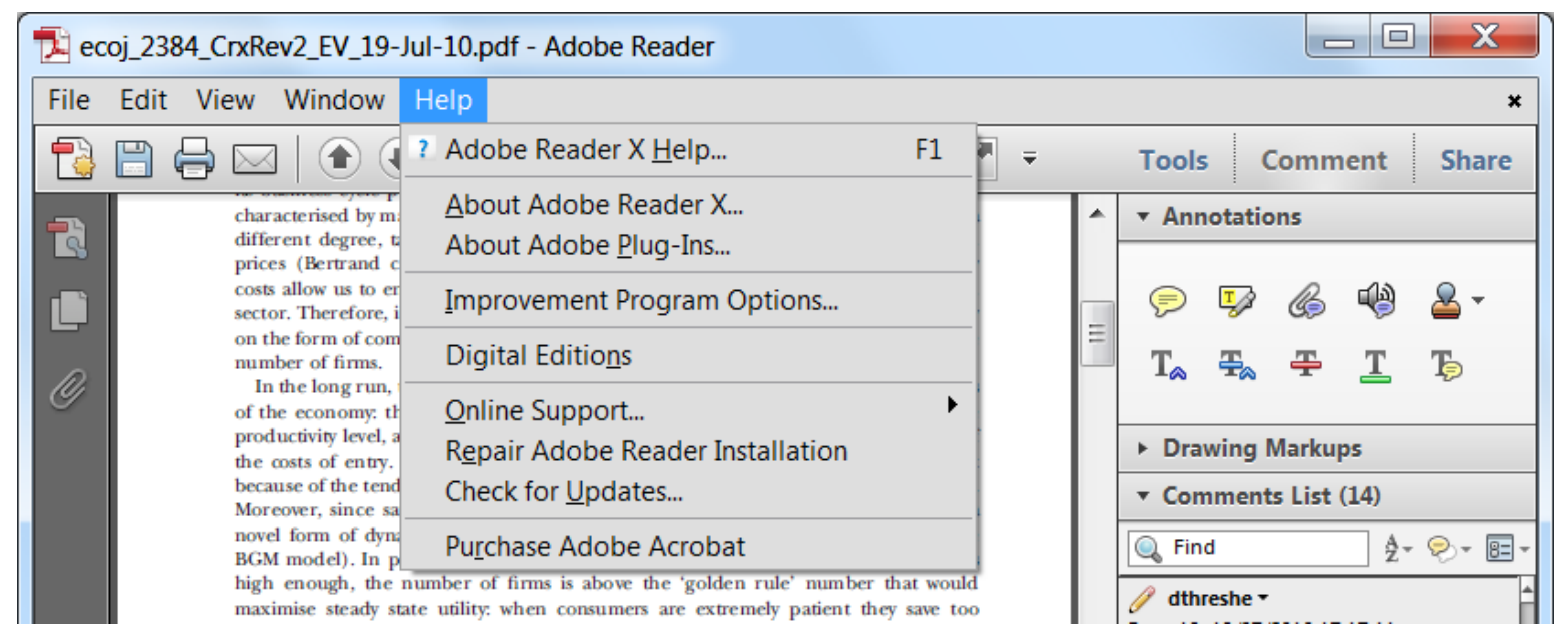

